\title{
Developing a Reactor Operator Training Course Series at Oregon State Uni- versity
}

\section{Dr. Wade R. Marcum, Oregon State University}

Assistant Professor

Department of Nuclear Engineering \& Radiation health Physics

Areas of expertise lie within fluid-structure interactions, experimental thermal-hydraulics, turbulence, reactor safety, system modeling, and advanced nuclear reactor concepts.

\section{Dr. Steve Reese, Oregon State University}

Dr. Reese is the Director for the Oregon State University Radiation Center and instructor in the Department of Nuclear Engineering and Radiation Health Physics. The Radiation Center is a multifaceted research facility specializing in research related to the nuclear sciences. The facility houses unique capabilities including the 1.1 MW Oregon State TRIGA Reactor (OSTR), gamma irradiator, thermal hydraulics testing laboratories, radiochemistry laboratories, and extensive radiological spectral and counting equipment. His research focus includes neutron radiography, MCNP, and reactor dosimetry. He obtained a PhD from Colorado State University (1997) in Radiological Health Sciences and a BS from Oregon State University (1991) in General Science. He also holds a Senior Reactor Operating license for the OSTR. He is certified by the American Board of Health Physics and is a member of the Organization of Training, Research, and Test Reactor Executive Committee. Previously, Dr. Reese served as the Reactor Administrator of the OSTR for seven years. Prior to that he served as a Research Scientist at Battelle Pacific Northwest National Laboratory. Research activities at Battelle centered on development of a CR-39 automated counting system for low energy neutron environments and responsibility for nuclear accident dosimetry technical evaluations and measurements. He completed his Bachelor's degree in General Science at Oregon State University and obtained a Ph.D. in Radiological Health Sciences from Colorado State University.

\section{Mr. Robert A Schickler}




\title{
Developing a Reactor Operator Training Course Series at Oregon State University
}

\author{
Wade R. Marcum ${ }^{1}$, Steve R. Reese ${ }^{2}$, S. Todd Keller ${ }^{2}$, Robert A. Schickler ${ }^{2}$ \\ ${ }^{1}$ Department of Nuclear Engineering and Radiation Health Physics, Oregon State University \\ ${ }^{2}$ Radiation Center, Oregon State University
}

\begin{abstract}
Oregon State University's (OSU's) Department of Nuclear Engineering and Radiation Health Physics (NERHP) recently graduated its first influx of students participating in the inaugural "Reactor Operator Training” course series. This course series was designed and implemented to provide students a unique opportunity to acquire hands-on experience interacting and engaging in operations and maintenance activities of a functioning research reactor. Students who successfully completed all requirements identified within the course series were afforded the opportunity to be tested by the U.S. Nuclear Regulatory Commission (USNRC) and acquire a Reactor Operator License on the Oregon State TRIGA ${ }^{\circledR}$ Reactor (OSTR). Five students completed all requirements and are presently USNRC licensed reactor operators at the OSTR.

Oregon State University houses one of only 30 functioning civilian research and test reactors in the United States. Facilitating this opportunity for nuclear science and engineering students provides an additional hands-on experience in a practical working environment that is intended to give these individuals a significant 'leg-up' as they begin their careers. The staff and faculty that interact with these select students have observed significant improvement in students' synthesis of information from a practical perspective. It is these traits that make students competitive when applying for jobs upon graduation and begin to professionally contribute to society.
\end{abstract}

\section{INTRODUCTION}

The Radiation Center (RC) building, located on the Oregon State University campus, houses the Oregon State TRIGA ${ }^{\circledR}$ Reactor (OSTR). The OSTR is a TRIGA ${ }^{\circledR}$ Mark II Reactor pool-type research reactor designed by General Atomics. The primary mission of the OSTR is “...to serve as the campus wide teaching, research, and service facility for programs involving the use of ionizing radiation and radioactive materials." The reactor core is located below approximately 4.87 meters of water, centrally located within an aluminum tank surrounded by a thick concrete biological shield. The OSTR is licensed to operate at a maximum of $1.1 \mathrm{MW}$ of thermal energy. The licensed power level of the OSTR is sufficiently low such that forced cooling is not required; as a result, the reactor is cooled via natural convection [1]. The inherent design traits of TRIGA $^{\circledR}$ Reactors enable such facilities to function as fantastic educational tools for young aspiring nuclear engineers and potential, future reactor operators.

In addition to housing the OSTR, the Radiation Center building also provides space for the Department of Nuclear Engineering and Radiation Health Physics (NERHP). These two entities (RC and NERHP) function autonomously, while synergistically collaborating when common short and/or long term goals align. OSU's NERHP function is '...to educate students within the field of nuclear science and engineering and conduct world class research'. In 2011 faculty and staff from within the NERHP and RC, respectively, began a collaborative effort of creating a two course series ("Reactor Operator Training I" and "Reactor Operator Training II") to educate 
students on fundamentals of nuclear reactor theory, apply this knowledge toward the OSTR, and develop skills sufficient to function as a reactor operator. The desired tangible outcome of this effort was to successfully matriculate select students who demonstrated the required skillsets through the training program and afford each individual the opportunity to be examined by the U.S. Nuclear Regulatory Commission (USNRC) as a licensed reactor operator.

\section{COURSE SERIES OVERVIEW}

The OSU NERHP presently has approximately 260 enrolled undergraduate students. The faculty and staff became aware that not all students who enroll in the course into the program would have sufficient time to perform critical training tasks, such as logged control panel hours, reactivity manipulations, and maintenance support. As a result it was decided to include a down selection process within the course series, allowing only a select number of students that participated in the first course an opportunity to continue with the second course. The intention at the highest level was to educate all students (within the first course) on nuclear reactor operations topics that translate to any reactor, and then focus more on the specifics of the OSTR in the second course.

The program was developed from a bottom-up approach. First, the requirements for licensing by the USNRC for licensed reactor operators were explicitly identified. These requirements are broken into top-level sections; the Written Examination: Operators (defined in 10CFR 55.41 [2]) including fourteen delineated subsections, and the Operator Tests (defined in 10CRF 55.45 [2]) which includes thirteen subsection topics to be addressed. These 27 subsections provided a skeletal outline for the course series learning objectives. In order to create a cohesive outline that facilitates maximum learning opportunity for students, topics were then rearranged amongst the 27 subsections to start at a broad-level and narrow to a specific focus on the OSTR. In addition to the formal knowledge requirements set forth by the USNRC, precedence within the Reactor Operating Staff at OSU has led to additional informal requirements for its trainees in order to ensure their success during license examination and licensed operational activities. These activities and attributes were added into the outline as well. Lastly, the outline was formed into a schedule taking place over two discrete terms.

\subsection{Reactor Operator Training I Course}

Reactor Operator Training I (ROT-I) course was limited to students having satisfied prerequisite courses associated with undergraduate level nuclear detection and mathematical differential equations. The skills developed in these two courses were decided to provide sufficient background for undergraduate students entering into the course series; however the class was opened up to graduate students as well in order to provide all students who have sufficient background the opportunity to become more acquainted with the OSTR and informed on nuclear reactor operations.

The primary emphasis of the first course focuses on developing knowledge and appreciation for the design and operating characteristics of the OSTR. During this course students must demonstrate the ability to:

- Understand fundamental reactor theory including decay and build-up of nuclides, neutron interactions and multiplication factor, reactor physics, reactor kinetics, and fundamental thermal hydraulics. 
- Apply reactor theory knowledge to the OSTR including core excess and shutdown margin, reactivity worth of control rods, control rod height prediction to go critical, fluid temperature rise through core, and fuel element centerline temperature.

- Demonstrate comprehensive understanding of the OSTR facility systems including core components, irradiation facilities, reactor water systems, secondary system, heating and ventilation system, plumbing, and radiological hazards and protection.

- Develop knowledge of fundamental theoretical methods used for the assessment of radiological protection at the OSTR including point source dose and activity.

- Understand the equipment and tools available at the OSTR used for radiological protection including area radiation monitors, neutron detectors, Geiger-Mueller detectors, and proportional counters

All material sufficient to support the course learning objectives was created in-house including that of a four volume training manual that covers topics 'general description of facilities', 'instrumentation and controls', 'reactor physics, kinetics, and characteristics', and 'radiological protection' [3]. Per the process used to create the schedule, the topics identified for ROT-I include those identified in Table 1. The course was broken into three, one hour sessions per week. Each week included two hours of lecture (Monday and Wednesday) followed by a hour tour (Friday) of various reactor facilities. The tour emphasized the material taught in class that week (e.g. Week 7 included a tour of beam lines).

Table 1: Schedule of topics for ROT-I

\begin{tabular}{|c|l|}
\hline Week & \multicolumn{1}{|c|}{ Topic } \\
\hline 1 & Reactor Overview \\
\hline 2 & Decay and Build-up of Nuclides \\
\hline 3 & Neutron Interactions \& Multiplication Factor \\
\hline 4 & Neutron Interactions \& Multiplication Factor \\
\hline 5 & Reactor Physics \& Reactor Kinetics \\
\hline 6 & Fundamental Thermal Hydraulics \\
\hline 7 & Core Components \& Irradiation Facilities \\
\hline 8 & Reactor Water Systems, Reactor Building \\
\hline 9 & Ventilation System \\
\hline 10 & Radiological Hazards \& Protection \\
\hline
\end{tabular}

Note that although the discussion during lectures and tours did include the OSTR, those topics identified within Table 1 are more fundamental in nature. Therefore those students who participated in ROT-I, but did not participate in Reactor Operator Training II (ROT-II) left the course with an increased level of understanding centered on general reactor operations principles and functions.

During the 2011 academic year, 32 students participated in the ROT-I course. Based on numerous discussions between the staff and faculty, it was decided that five students would be admitted into ROT-II. Limiting enrollment in ROT-II to five students provided the opportunity for each student to have an entire day of individualized attention while training on the reactor console. Of the 32 students who participated in the ROT-I course, 24 were interested in participating in ROT-II. The down selection process included three criteria that were evenly 
weighted; (1) individual student's standing in class during week 10 of ROT-I course, (2) duration that students were present at OSU after completing course series, and (3) content identified within each student's statement of interest. The third criterion was found to be the most valuable in the selection process. The premise of the statement of interest assignment was to have each student to synthesize their career thoughts and aspirations and how that relates to the ROT-II course. Of the 24 students who were interested in participating in ROT-II, five were down selected.

\subsection{Reactor Operator Training II Course}

This course was the second of a two term sequence aimed to provide the most successful students in ROT-I the opportunity to acquire a reactor operator's license at the OSTR. The primary emphasis of this course (ROT-II) was to develop knowledge of operating characteristics as well as design and license limitations of the OSTR. During this course students must have demonstrated the ability to:

- Acquire comprehensive understanding of advanced reactor theory as it applies to the OSTR which enables the analysis of core excess and shutdown margin, reactivity worth of control rods, control rod height prediction to go critical, fluid temperature rise through core, and fuel element centerline temperature.

- Develop knowledge of all systems and subsystems associated with the OSTR and apply this knowledge during supervised reactor operations including core components, irradiation facilities, reactor water systems, secondary system, heating and ventilation system, plumbing, and radiological hazards and protection.

- Retain relations between design limitations, operational limitations, and license limitations of the OSTR as defined within the Technical Specifications.

- Critically discuss the basis for which operational limitations and license limitations have been selected for the OSTR.

- Demonstrate the ability to successfully perform actual operational items such as startup and shutdown checklists, operations logs, irradiation sample loading and removal, fuel handling, and other related events

The ROT-II course was organized with a completely different perspective from that of ROT-I. A schedule was create that enabled each student a single day of the week (Monday through Friday) to devote their time for hands-on operational activities. Particular emphasis was placed on reactor operations participation during the morning and afternoon period in order to facilitate engagement with the reactor during start-up and shutdown. Two lecture sessions were provided each week with a single lecture topic being repeated each session. This organizational structure allowed for all students to perform operational activities on the OSTR control panel along with being afforded the classroom setting time. Each week a unique topic was focused upon. These topics were intended to be much more directed toward the OSTR relative to that of the topics presented within the ROT-I course. Topics covered within ROT-II are presented in Table 2.

Although a few traditionally delivered course assignments were provided within ROT-II, the majority of the course was evaluated based on each reactor operator trainee's 'log book'. The 'log book' was created specifically for the ROT-II course to hold students accountable and document unique activities associated with the OSTR that are an essential component of the knowledge base necessary for a licensed reactor operator. 
Table 2: Schedule of topics for ROT-II

\begin{tabular}{|c|l|}
\hline Week & \multicolumn{1}{|c|}{ Topic } \\
\hline 1 & Radiation Safety Training \\
\hline 2 & Radiation Safety Training, Instrumentation \\
\hline 3 & Instrumentation \\
\hline 4 & Primary and Secondary System \\
\hline 5 & Ventilation System \\
\hline 6 & Safety Analysis Report \\
\hline 7 & Safety Analysis Report \\
\hline 8 & Technical Specifications Review \\
\hline 9 & Operating Procedures Review \\
\hline 10 & Emergency Response Plan \\
\hline
\end{tabular}

An example page from the activity log book is shown in Fig. 1. Each student was required to have each activity signed and dated by the supervising licensed reactor operator in order to have satisfied completion of said activity. In reflection, this log book provided additional benefit to the course structure by documenting the activities necessary to supplement the reactor operator license application request submitted to the USNRC.

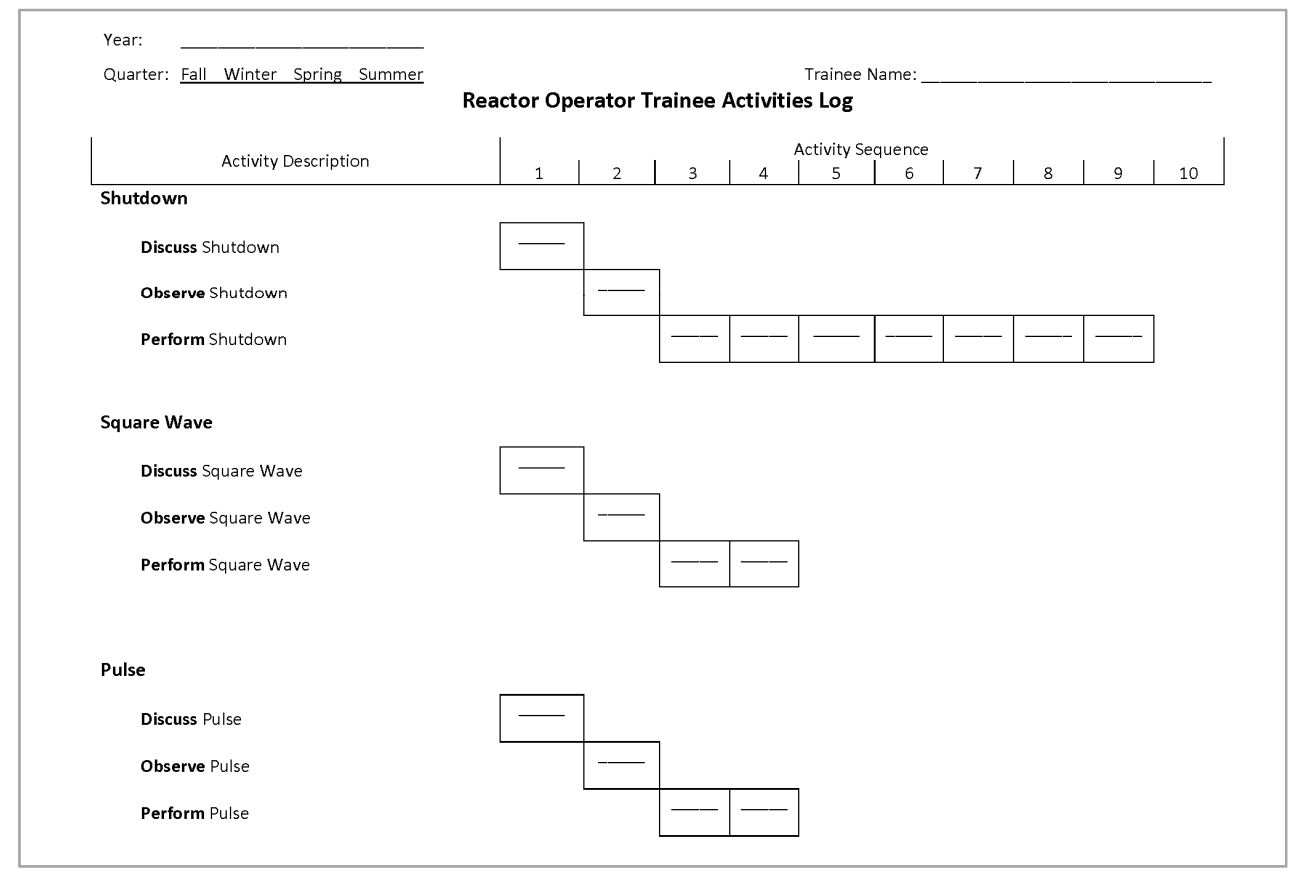

Fig. 1: Example page from Activity Log

As the ROT-II course progressed, the OSTR staff made a conscious effort to create a more autonomous role for each trainee during their control panel activities. The final exam for the ROT-II course was intended to follow the structure and content of a USNRC proctored exam as closely as possible. Each student was tested individually for their final exam, while being provided two separate examination components (written and operations). The written 
examination was created using the same format, and similar questions that have been provided in previous reactor operator examinations proctored by the USNRC. Structuring the exam in this manner proved to be the most critical and beneficial experience in preparation for the NRC examination.

\section{TYING IT ALL TOGEHER}

A reactor operator training course program has been successfully implemented within a number of university-based programs and shown to provide tangible benefits to students who leave the university setting. The course series and training program put together at Oregon State University required a significant component of cooperation and support by both NERHP Faculty and RC staff in order to enable similar benefits for OSU students. This coordination included the overall alignment of expectations that students are held to in order to be afforded the opportunity to take an examination by the NRC. The overall process that was established as a part of this program is outlined in Fig. 2.

Decisions on the configuration of the class were driven from two perspectives; first (and most important), making sure that each student participating in either ROT-II or both ROT-I and ROT-II left the course series having a positive experience and a strong fundamental and operational reactor knowledge base; second to maintain integrity within the reactor operator training experience associated with the OSTR. Based on numerous conversations, and daily interactions between staff, faculty and students, the course series culminated with a 100\% success rate in successfully licensed nuclear reactor operators and a newly developed program at the OSU NERHP.

\section{REFERENCES}

1. Marcum, W.R., et al., Steady State Thermal Hydraulic Analysis of the Oregon State TRIGA Reactor Using RELAP5-3D. Nuclear Science and Engineering, 2009. 162: p. 261274.

2. Part 55 - Operators' Licenses. 2007, Nuclear Regulatory Commission.

3. Oregon State TRIGA Reactor Training Manual. 2011, Corvallis: Oregon State University. 


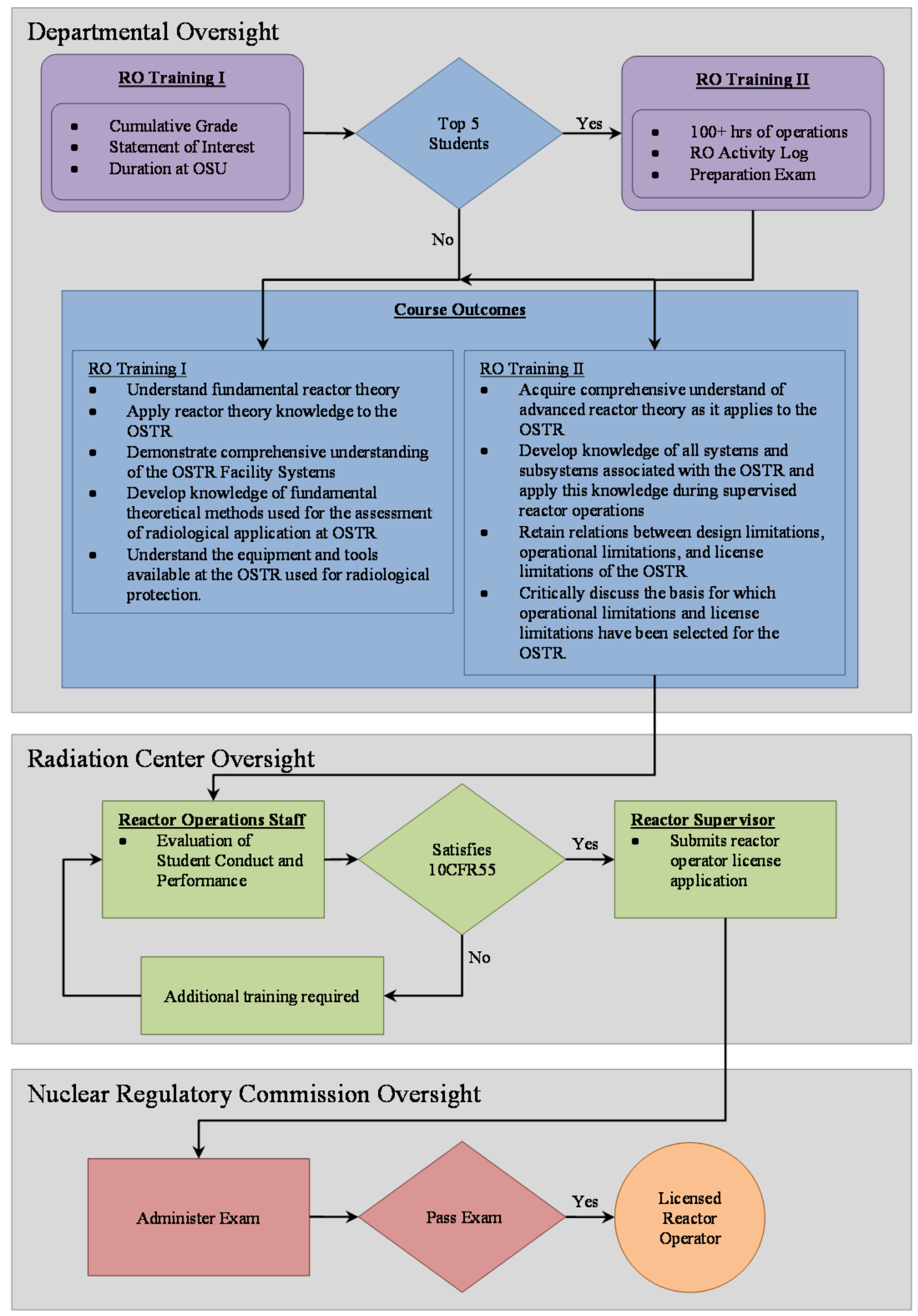

Fig. 2: Outline of structure and outcomes of RO Training Course Series 